\title{
Mulheres na Computação: Uma Análise da Participação Feminina nos Cursos de Licenciatura em Computação
}

\author{
Wilk Oliveira dos Santos ${ }^{1}$
}

${ }^{1}$ Núcleo de Excelência em Tecnologias Sociais (NEES) - Instituto de Computação (IC) Universidade Federal de Alagoas (UFAL) - Maceió - AL - Brasil

woseic.ufal.br

\begin{abstract}
Resumo. A inclusão das novas tecnologias digitais nos mais diferentes contextos sociais tem alterado substancialmente a forma como as atividades cotidianas têm sido feitas, inclusive nos contextos educacionais, fazendo surgir o curso de Licenciatura em Computação. Ao mesmo tempo, ao longo da história, as mulheres tem tido participação substancial neste fenômeno. Assim, $o$ presente artigo apresenta um estudo com o intuito de analisar a participação dos discentes, com ênfase no perfil feminino, nos cursos de Licenciatura em Computação no Brasil. Os principais índices indicam a baixa participação destas estudantes em comparação com o publico masculino, e a necessidade de políticas de fomento com intuito de aumentar a participação feminina no curso.
\end{abstract}

Abstract. The inclusion of the new digital technologies in the most different social contexts has substantially altered the way in which daily activities have been done, including in the educational contexts, giving rise to a degree in Computer Science. Throughout history, women have had a substantial participation in this phenomenon. Thus, this paper presents a study with the intention of analyzing the participation of the female students in the Brazilian courses of Computer Science degree. The main finds indicate low participation of women in comparison with man in the course of Computer Science degree, highlighting the importance of to create political to promote the women participation in this course.

\footnotetext{
${ }^{1}$ Mestre em Informática pela Universidade Federal de Alagoas (UFAL) com período sanduíche na University of Saskatchewan (U of S - Canadá). Graduado em Licenciatura em Computação pela Universidade de Pernambuco (UPE). É Pesquisador do Núcleo de Excelência em Tecnologias Sociais (NEES) e do Multi-Agent Distributed Mobile and Ubiquitous Computing Lab (MADMUC - Canadá). Currículo Completo: https://goo.gl/bkhN8N Site pessoal: https://goo.gl/u4eZH6
} 
VI Congresso Brasileiro de Informática na Educação (CBIE 2017)

Anais dos Workshops do VI Congresso Brasileiro de Informática na Educação (WCBIE 2017)

\section{Introdução}

Desde os princípios da Computação, as mulheres têm tido participação fundamental em sua descoberta e evolução. Um dos casos mais famosos é o do ENIAC (primeiro computador digital eletrônico de grande escala), onde, de acordo com Light [1999], quase 200 jovens mulheres trabalharam como "computadores humanos", realizando cálculos de balística durante a Segunda Guerra Mundial. Dessas, seis foram selecionadas para programar o ENIAC que, ironicamente, apagaria seus nomes e se tornaria muito mais famoso do que suas projetistas. Assim, ao longo do tempo, diversas outras mulheres tiveram participação fundamental na evolução da Computação.

Apesar do fundamental papel das mulheres ao longo da evolução da Computação, a desigualdade de gênero se faz ainda mais evidente [Heinzmann et al. 2017]. Conforme a pesquisa realizada pelo PNAD - IBGE em 2009, 79\% das mulheres que ingressam em cursos acadêmicos ligados a Computação não concluem o curso, e apenas $20 \%$ dos profissionais de Tecnologia da Informação no Brasil são mulheres, não tendo grandes mudanças nesta situação, mesmo depois de quase uma década.

Com o intuito de ampliar o número de mulheres interessadas pela Computação, o Ministério da Ciência, Tecnologia e Inovação em 2013, lançou o Programa Ensino Médio Inovador, onde buscavam incentivar principalmente meninas cursando o ensino médio ou a graduação a inserir-se na área, além de permanecer na mesma. Este projeto culminou em diferentes ações ligadas ao incentivo da participação feminina nos cursos de Ciências Exatas e, por conseguinte, no próprio curso de Licenciatura em Computação.

Ao mesmo tempo, diante da evolução da Computação enquanto fenômeno social, a inclusão da mesma como um elemento complementar de estudo e apoio interdisciplinar na Educação Básica, a partir da Lei de Diretrizes e Bases do Ensino Nacional [LDB 9496/1996], alterou o panorama da educação nacional. Além disso, o Plano Nacional de Educação [PNE 2014-2024] tem também fomentado a informatização da escola propondo a ampliação do número de laboratórios de Informática (Estratégia 6.2). Por via deste respaldo legal, tem surgido um novo tipo de profissional, o professor de Computação ou Informática educativa em nível de ensino fundamental e médio, formado pelo curso de Licenciatura em Computação.

Em adição, o professor de Computação, mais propriamente, o Licenciado em Computação é um profissional formado por curso de graduação denominado Licenciatura em Computação, e é quem está, segundo Matos e Silva [2012], habilitado para atuar de forma integradora na Educação Básica em todos os níveis de ensino da área. Isso diz respeito tanto ao uso, como o desenvolvimento de novas tecnologias educacionais - software, Objetos de Aprendizagem -, quanto ao ensino de Computação no seu viés científico.

A Licenciatura em Computação foi inicialmente ofertada pela Universidade de Brasília - UnB no ano de 1997. Sua segunda oferta foi em 1999 na Universidade de Santa Cruz do Sul - UNISC; após 2012, houve um grande crescimento de ofertas e, atualmente, o Ministério de Educação e Cultura - MEC afirma existir mais de 150 cursos no Brasil. Um estudo de Cruz et. al [2016] analisou o curso de Licenciatura em 
Computação na sua dimensão curricular. Este revelou-nos o curso como completo no sentido da formação profissional; o currículo, segundo Cruz et. al [2016], integra a própria Computação com a Educação, Matemática, Psicologia, Sociologia, Filosofia, Línguas Portuguesa e Inglesa, demonstrando que sua principal característica é a multidisciplinaridade.

Contudo, a profissão de Licenciado em Computação não se encontra em solidez; são poucos os espaços legalmente constituídos nas empresas e como professor de Computação na Educação Básica. Castro e Vilarim [2013] consideram que a Licenciatura em Computação enfrenta dificuldades de identificação: o que faz? O que ensina? Além disso, a adequação pedagógica dentro das escolas, questões de mercado e o reconhecimento da profissão são questões desafiadoras para o curso de graduação. Ao mesmo tempo, diante da importância das mulheres na história da Computação, tem-se perguntado sobre a participação estudantes da graduação do sexo feminino neste curso.

Sob este contexto, o presente artigo propõe-se analisar e discutir a participação dos discentes do sexo feminino nos cursos de Licenciatura em Computação, tomando como base uma pesquisa realizada em relatórios recentes da Sociedade Brasileira de Computação (SBC). Os resultados deste estudo revelam que apesar de dentre os cursos de Computação, o curso de Licenciatura em Computação ter maior participação de estudantes do sexo feminino, este ainda é substancialmente menor que os estudantes do sexo masculino, trazendo à tona a importância do fomento da participação feminina nestes cursos.

\section{Revisão da Literatura}

Esta seção contempla a revisão dos principais tópicos abordados neste artigo, sendo mulheres na Computação e a Licenciatura em Computação.

\subsection{Mulheres na Computação}

A presença feminina na Computação (assim como em outras ciências) tem sido longamente estudada e discutida [Oliveira et al. 2014]. A Computação (assim como outras áreas das Ciências Exatas), de acordo com o mesmo autor tem sofrido com o estigma (e talvez preconceito) de ser uma área difícil de estudar, fazendo os cursos lidarem com o pouco interesse de candidatos ao ensino superior, bem como, com a grande evasão dos estudantes que inicialmente optaram pela área.

De acordo com o mais recente estudo da SBC, nos curso de Computação em geral, a presença de discentes do sexo masculino é amplamente superior ao feminino. Dentro das discussões sobre as mulheres na Computação, ao mesmo tempo, Medeiros [2005] em um dos primeiros estudos Brasileiros neste domínio, já destacava ações que podem ser realizadas para permitir que mulheres brasileiras se tornem agentes plenas na sociedade da informação, envolvendo meios formais e informais de educação, para fomento desta causa, por exemplo: (i) desenvolver um censo nacional abrangente sobre mulheres e Tecnologia da Informação, (ii) oferecer educação informal para toda a família, com ênfase nos pais e responsáveis, destacando as vantagens de trabalho em Tecnologia da Informação, e como isto oferecer uma boa oportunidade para as 
VI Congresso Brasileiro de Informática na Educação (CBIE 2017)

Anais dos Workshops do VI Congresso Brasileiro de Informática na Educação (WCBIE 2017)

mulheres, e (iii) promover as bases para uma formação adequada para meninas e professores(as).

Em um raciocínio semelhante, estudos recentes buscam colocar em prática algumas dessas ações. Maciel e Bim [2016], por exemplo, destacam ações para divulgar a Computação para meninas no ensino médio, assim como Maciel et al. [2012], também promoveram ações no sentido de divulgar a área de Computação para meninas no ensino médio, buscando assim, aumentar a procura de meninas por cursos ligados a Computação.

\subsection{Licenciatura em Computação}

O curso de Licenciatura em Computação atende à demanda de formação de professores capazes de operar no uso e desenvolvimento de tecnologias para a educação, bem como ensinar a Computação na escola. Com o reconhecimento do Ministério da Educação MEC, o curso é reconhecido pelas seguintes nomenclaturas: Licenciatura em Computação, Licenciatura em Ciência da Computação, Licenciatura em Informática, Informática - Licenciatura, Licenciatura Plena em Informática e outras. Estas variações, no entanto, geram dúvidas e discussão etimológica da denominação do curso.

Neste estudo, optou-se por referir-se ao curso como Licenciatura em Computação, tendo por base o último relatório Sociedade Brasileira de Computação SBC, que considera como Licenciatura em Computação todos os cursos de "formação de professores para a área de Computação". Ao mesmo tempo, a utilização predominante do termo "Computação" neste artigo justifica-se pelo interesse dos autores em evidenciar o seu caráter científico do ensino dentro da Educação Básica; é muito importante o reconhecimento da Computação nas escolas como o ensino e aplicação de teorias relacionadas ao processo de resolução de problemas, furtando-se somente da instrução para uso aplicativos.

Nesse aspecto, os Referenciais de Formação em Computação - RFC determinam as áreas de atuação do Licenciado em Computação. Segundo o documento, estes podem atuar em escolas e empresas, bem como, outras instituições de dois modos: i) como professores de Computação, ensinando desde Informática básica até aspectos relacionados ao pensamento/raciocínio computacional, à robótica e ao desenvolvimento de algoritmos e software; ou ii) como agentes integradores $e$ promotores do uso da tecnologia na educação, trabalhando de maneira interdisciplinar na gestão e desenvolvimento de recursos de hardware e software utilizados para ensino e aprendizagem no âmbito da educação presencial ou a distância, dentre outras maneiras substanciais a sociedade atual.

Além disso, os RFC ainda destacam que o Licenciado deve dominar os fundamentos da Computação relacionados à Matemática, considerando que eles possuem origem e contexto históricos com distintos modos de realizabilidade técnica; deve ser capaz de explorar e investigar temas ligados ao pensamento/raciocínio computacional, como a abstração, a complexidade e mudança evolucionária; é responsável por apresentar a Computação como ciência à escola e à sociedade, auxiliando na construção de narrativas que deem sentido e significado aos conceitos e 
VI Congresso Brasileiro de Informática na Educação (CBIE 2017)

Anais dos Workshops do VI Congresso Brasileiro de Informática na Educação (WCBIE 2017)

fenômenos da Computação.

\section{Análises dos Dados}

Nos últimos anos, as ofertas dos cursos de Licenciatura em Computação têm crescido de maneira substancial, em todas as regiões do país, tendo, no entanto, a região Nordeste com maior número de cursos criados entre os anos de 1997 e 2015, como pode ser observado na Figura 1. Ao mesmo tempo é possível perceber que o maior crescimento do curso, ocorreu no ano de 2010, com 27 cursos criados, sendo também a maioria na região nordeste do Brasil.

Diante destes dados, é possível perceber uma tendência real de crescimento do curso, dentro do cenário de evolução dos cursos da área de Computação. No entanto, é possível também perceber que este crescimento não é uniforme em relação às diferentes regiões do Brasil. Apesar do grande crescimento na região Nordeste, a região Centro Oeste, por exemplo, que teve uma evolução grande nos primos anos de formação dos cursos, de modo especial no ano de 2001, com sete cursos criados. A região norte por outro lado, que nos primeiros anos não teve um alto índice de crescimento, nos últimos anos tem mudado este cenário, a exemplo do ano de 2015 com dois cursos criados, porém sendo a única região que ingressou novas turmas do curso.

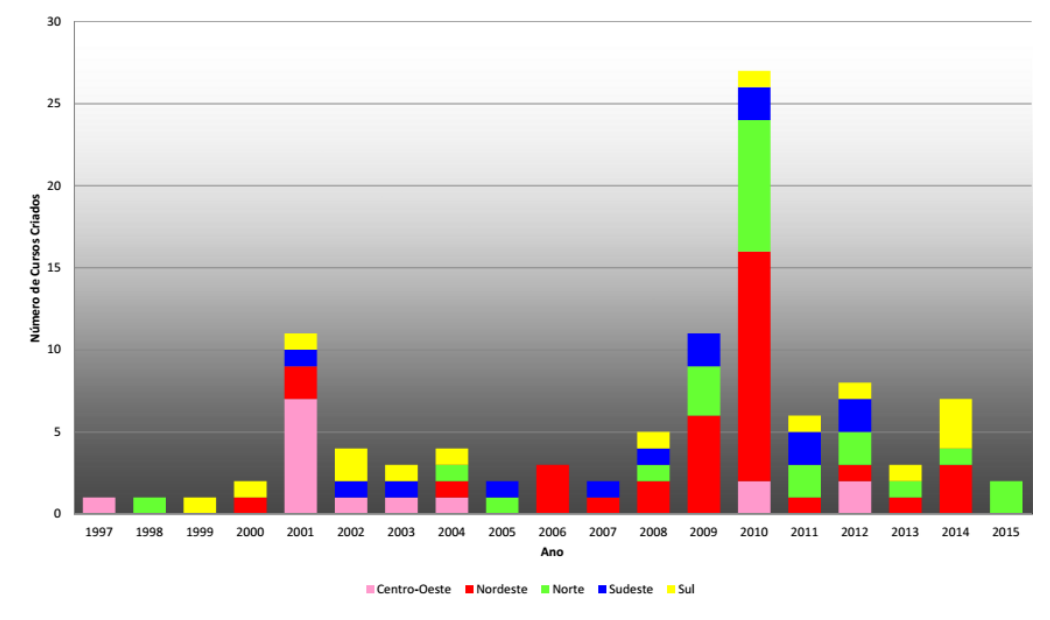

Figura 1. Evolução de oferta dos cursos de Computação (fonte: Sociedade Brasileira de Computação)

Apesar do crescimento e evolução do curso, na perspectiva dos cursos ligados a computação no Brasil, constatadas anteriormente, é possível notar claramente que a maioria dos ingressantes nos cursos pertence é do sexo masculino. Desde o primeiro ano constado avaliado (2001), os discentes pertencentes ao sexo masculino representaram a maioria dos ingressantes, sendo estes mais que a metade dos ingressantes, como é possível identificar na

Figura 2, que mostra a evolução do perfil dos ingressantes do acordo com seu sexo. 
VI Congresso Brasileiro de Informática na Educação (CBIE 2017)

Anais dos Workshops do VI Congresso Brasileiro de Informática na Educação (WCBIE 2017)

Além disso, ao longo dos anos, é possível notar que a evolução na quantidade de ingressantes é representada basicamente pelo público masculino. Ao longo de 14 anos de avaliação, a quantidade de ingressantes do sexo feminino tem se mantido praticamente constante, representando em torno de 50000 (cinquenta mil) ingressos por ano. Por outro lado, o ingresso do público tem evoluído de forma gradativa, representando, atualmente um valor cinco vezes maior que o feminino nos cursos de Licenciatura em Computação.

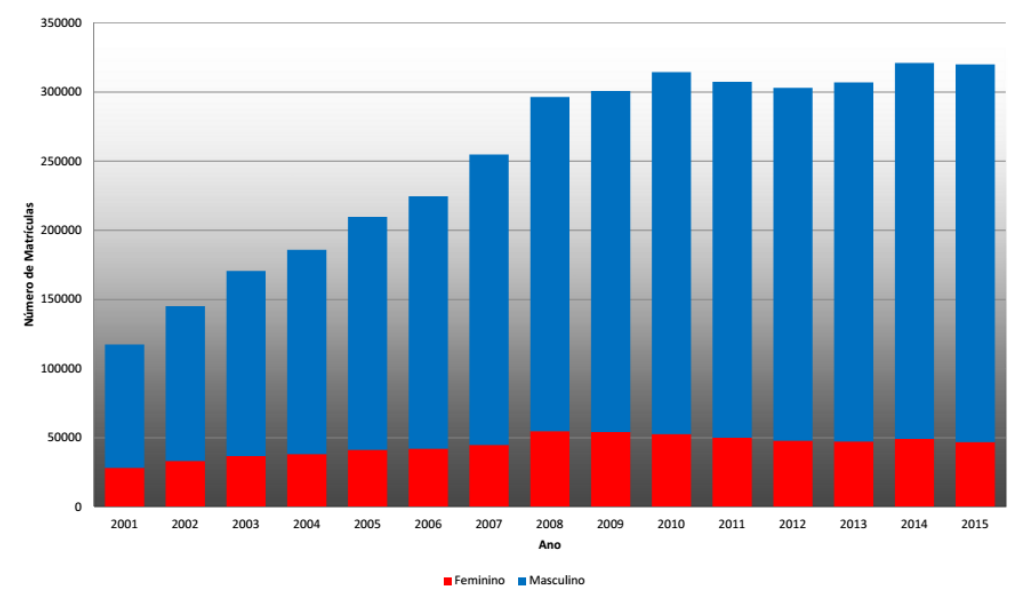

Figura 2. Evolução das Matriculas por Sexo (fonte: Sociedade Brasileira de Computação)

Os gráficos das Figuras 2 e 3 apresentam ainda que se teve entre os anos de 2001 e 2015, em média, 50 mil ingressos de meninas por ano, mas apenas 4 mil concluintes por ano. Quantitativamente, estes dados representam uma significativa proporção em relação a evasão de estudantes do sexo feminino do curso. Em outras palavras, uma grande parcela das meninas que têm ingressado no curso, por algum motivo, tem desistido de sua formação em Licenciatura em Computação, necessitando de uma profunda análise para melhor entender esta problemática.

Em comparação com outros cursos da área de Computação, como pode ser observado na

Figura 3, apesar da pouca procura feminina pelo curso de Licenciatura em Computação esta sendo baixa ao longo dos anos, tem sido proporcional a procura pelos demais cursos da área de Computação. Neste sentido, fica claro que a baixa procura por parte das mulheres, continua a ser uma situação presente nos curso da área de Computação. 
VI Congresso Brasileiro de Informática na Educação (CBIE 2017)

Anais dos Workshops do VI Congresso Brasileiro de Informática na Educação (WCBIE 2017)

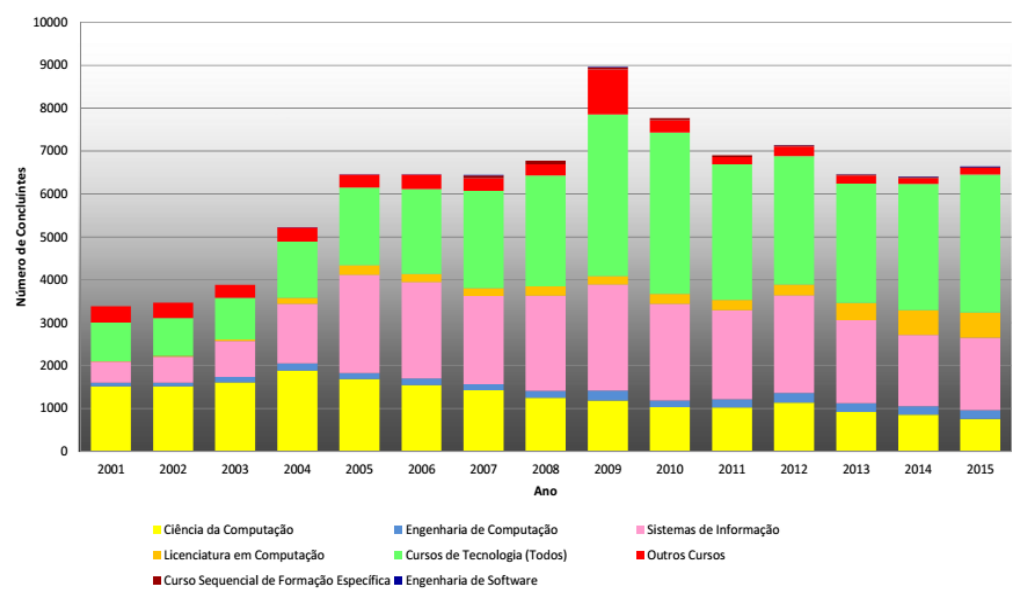

Figura 3 Evolução da Participação Feminina por Curso (fonte: Sociedade Brasileira de Computação)

De modo geral, os cursos da área de Computação continuam a receber uma baixa procura por parte das mulheres. Assim como os demais cursos deste domínio, o curso de Licenciatura em Computação tem uma procura altamente desigual, tendo em algumas situações o público masculinos cinco vezes maiores que o feminino, confirmando uma situação recorrente não somente entre os cursos da área de Computação, mas com os cursos de exatas em geral.

Neste sentido, os resultados indicam que apesar dos recentes esforços no intuito de propagar o curso de Licenciatura em Computação, assim como os demais cursos da área de Computação, ainda não têm surgido resultados satisfatórios, se fazendo cada vez mais necessário, a realização de atividades com o intuito de fomentar a maior participação de meninas, no intuito de proporcionar uma igualdade entre seu público, bem como, proporcionar uma distribuição mais uniforme dos profissionais formados no mercado de trabalho.

Diante deste cenário, destaca-se como recomendações $(i)$ criação e fomento de politicas públicas que visem incentivar a igualdade de gêneros nos cursos de graduação, e, por conseguinte nos cursos de Licenciatura em Computação, (ii) ações internas (ligadas a projetos de pesquisa, desenvolvimento, extensão e estágios) que busquem incentivar a participação feminina nos cursos de Licenciatura em Computação e, (iii) realização de projetos que visem identificar detalhes sobre o ingresso de estudantes no curso, buscando o desenvolvimento de solução pontuais no fomento a participação feminina no curso de Licenciatura em Computação.

\section{Limitações}

Apesar de se tratar de um estudo que analisou dados de um relatório sobre diferentes vertentes de evolução dos Cursos ligados a Computação, os dados foram obtidos mediante a realização de um estudo empírico secundário. De acordo com Wohlin et al. (2012), isto pode levar a geração natural de limitações ou ameaças à sua validade. Sendo assim, esta seção descreve as precauções para replicações futuras deste estudo e 
outros aspectos que devem ser levados em conta para generalizar os resultados. Em geral, tentou-se minimizar muitas das limitações discutidas durante este artigo. Para organizar esta seção, as limitações foram classificadas de acordo com as categorias descritas por Wohlin et al. [2012]: interna, externa, construção e conclusão.

Interna: Como o estudo envolveu a obtenção de dados advindos de um relatório externo, torna-se propenso a uma série de ameaças internas, como: (i) história - é possível que o momento em que o relatório inicial foi desenvolvido, alguma informação importante tenha ficado de fora; (ii) viés positivo/negativo - é possível que os organizadores do relatório, devido a idade e fatores culturais, entre outros, tenham uma visão pré-formada (positiva ou negativa sobre o objeto de estudo).

Externo: Fatores externos a esse estudo podem ter trazido limitações aos dados obtidos ou analisados. Um os fatores observados trata-se do levantamento inicial de dados e suas considerações, que podem afetar as análises finais. No intuito de mitigar estas limitações, foram usados apenas relatórios e estudos oficiais amplamente usados e reconhecidos pela comunidade de Informática na Educação e Educação em Computação.

Construção: As ameaças desta categoria estão relacionadas principalmente ao seguinte aspecto: o estudo apresentado neste trabalho analisa diferentes itens, partindo de trabalhos secundários, assim, alguns dados podem não ter sido considerados pelos condutores desse estudo. Para minimizar essas limitações, selecionamos metodologias e instrumentos empiricamente validados e utilizados comumente em estudos científicos pela comunidade.

Conclusão: As ameaças desta categoria estão relacionadas ao escopo do estudo. Neste sentido, é possível que os profissionais que realizaram as análises dos dados podem, por ventura, ter deixado de considerar algum aspecto, bem como, deixado de utilizar alguma técnica estatística, por exemplo, que pudessem trazer novas percepções e discussões quanto ao estudo. No intuito de mitigar estas ameaças, todo processo de análises foi discutido com profissionais de considerável tempo de formação e atuação na área do estudo.

\section{Considerações Finais}

Desde os princípios da Computação, as mulheres têm tido papel fundamental em todo seu processo evolutivo. Ao mesmo tempo, conforme visto, o curso de Licenciatura em Computação tem por objetivo formar professores para atuarem em todas as modalidades da Educação Básica na área de Computação; desde 1999 - ano da primeira oferta do curso - o currículo vem sendo reformulado visando atender os aspectos legais e necessidade do ensino. No entanto, a participação de discentes do sexo feminino em cursos de disciplinas exatas, de modo especial nos cursos ligados a Computação é considerada baixa e desproporcional aos discentes do sexo masculino, passando a ser estudada em diferentes perspectivas.

De forma geral, este estudo analisou a perspectiva de participação do público nos cursos de Licenciatura em Computação no Brasil. O estudo considerou os últimos relatórios da SBC, que mediram diferentes aspectos dos cursos ligados a Computação 
VI Congresso Brasileiro de Informática na Educação (CBIE 2017)

Anais dos Workshops do VI Congresso Brasileiro de Informática na Educação (WCBIE 2017)

no Brasil, por exemplo, o crescimento do ingresso de estudantes de acordo com o sexo. $\mathrm{O}$ estudo constatou que houve um crescimento de estudantes na graduação. E com isso, constatou uma estagnação nos últimos 14 anos, que representam a minoria dos ingressantes e concluintes do curso.

A partir dos argumentos supracitados, recomenda-se para trabalhos futuros o fomento a estudos que incentivem a maior participação feminina nos cursos de Licenciatura em Computação, tanto em aspectos pontuais, quanto as próprias políticas públicas, ligadas a projetos que possam incentivar a maior participação das mulheres nos cursos Licenciatura em Computação, em busca da igualdade de participação. Objetiva-se ainda a realização de estudos mais profundos diante dos dados obtidos, no intuito de identificar e discutir outras vertentes da participação feminina nos cursos de Licenciatura em Computação.

\section{Referências}

Brasil. Constituição da República Federativa do Brasil (1988) Disponível em < http://www.senado.gov.br/legislacao/const/con1988/con1988_05.10.1988/con1988.p df>. Acesso em: 07 de Maio de 2017.

Brasil. Ministério da Educação - MEC. (1996) "Lei de Diretrizes e Bases da Educação Nacional - LDB". http://www.planalto.gov.br/ccivil_03/leis/L9394.htm, Maio.

Brasil. Ministério da Educação - MEC. "Planejando a próxima década: conhecendo as 20 metas do Plano Nacional de Educação". (2014) http://pne.mec.gov.br/images/pdf/pne_conhecendo_20_metas.pdf, Maio.

Castro, C. S., \& de Oliveira Vilarim, G. (2013). Licenciatura em Computação no cenário nacional: embates, institucionalização e o nascimento de um novo curso. Revista Espaço Acadêmico, 13(148), 18-25.

Cruz, M. K., Becker, F., \& Hinterholz, L. (2016). Carga Horária Prática na Formação de Professores de Computação e Informática Educativa. In Anais do Workshop de Informática na Escola (Vol. 22, No. 1, p. 698).

Heinzmann, L., Romagna, M. E., Gosteinski, M. A., \& da Silva, J. M. (2017). Meninas e Jovens na Computação. Anais do Computer on the Beach, 554-558.

IBGE. (2009) "Pesquisa Nacional de Amostra Por Domicílio, Síntese de IndicadoresSociais".

IDC Brasil. (2015), "IDC Brasil aponta que mercado de TIC deve crescer 5\% e movimentar US\$ 165,6 bilhões no país em 2015”, http://br.idclatin.com/releases/news.aspx?id=1779. Acesso em 02 de Novembro de 2015

Light, J. S. (1999) "When Computer Were Women", Technology and Culture 40(3):455-483.

Maciel, C., \& Bim, S. A. (2017). Programa Meninas Digitais-ações para divulgar a Computação para meninas do ensino médio. Anais do Computer on the Beach, 327336. 
VI Congresso Brasileiro de Informática na Educação (CBIE 2017)

Anais dos Workshops do VI Congresso Brasileiro de Informática na Educação (WCBIE 2017)

Maciel, C., Bim, S. A., \& Boscarioli, C. (2012, November). A fantástica fábrica de chocolate: levando o sabor de IHC para meninas do ensino fundamental. In Companion Proceedings of the 11th Brazilian Symposium on Human Factors in Computing Systems (pp. 27-28). Brazilian Computer Society.

Matos, E., \& Silva, G. F. B. (2012). Currículo de licenciatura em Computação: uma reflexão sobre perfil de formação à luz dos referenciais curriculares da SBC. In XXXII Congresso da Sociedade Brasileira de Computação - XX Workshop de Educação em Computação.

Medeiros, C. B. (2005, June). From subject of change to agent of change: women and IT in Brazil. In Proceedings of the international symposium on Women and ICT: creating global transformation (p. 15). ACM.

Nunes, D. J. (2011). Ciência da Computação na Educação Básica, Disponível em: 〈http://www.adufrgs.org.br/artigos/ciencia-da-Computação-na-educacao-basica $>$. Acesso em 20 de Maio de 2017.

Nunes, D. J. (2015). Educação Superior em Computação, Estatísticas 2015. Sociedade Brasileira de Computação-SBC. Disponível em:< http://www.sbc.org.br/documentos-da-sbc/summary/133-estatisticas/1074-educacaosuperior-em-Computação-estatisticas-2015>. Acesso em, 06 de Maio de 2017.

Oliveira, A. C., Moro, M. M., \& Prates, R. O. (2014). Perfil feminino em computação: Análise inicial. In XXXIV Congresso da Sociedade Brasileira da ComputaçãoCSBC.

Papert, S., Valente, J. A., \& Bitelman, B. (1980). Logo: computadores e educação. Brasiliense.

Referenciais de Formação em Computação, Cap. V "Referenciais de Formação em Computação: Licenciatura em Computação". (2017) http://www.sbc.org.br/noticias/10-slideshow-noticias/1979-consulta-publica-sobreos-referenciais-de-formacao-em-Computação-da-sbc, Maio.

Scaico, P. D., Henrique, M. S., Cunha, F. O. M., \& de Alencar, Y. M. (2012). Um relato de experiências de estagiários da licenciatura em Computação com o ensino de Computação para crianças. RENOTE, 10(3).

Silva Neto, S. R., Santos, H. R. M., \& Santos, W. O. (2015) "ABILSEN: Uma Abordagem para Inclusão do Licenciado em Computação no Ensino Básico”. In: $23^{\circ}$ Workshop sobre Educação em Computação, p. 1-10.

Silva, S.F., Ferreira, A., Souza, A.A., Galdino, E., Oliveira, M.L.S., Neto, S. e Oliveira, W. (2015) "Relato de Experiência de Ensino de Computação no Ensino Fundamental em Estágio Supervisionado da Universidade de Pernambuco no Campus Garanhuns", In: $23^{\circ}$ Workshop sobre Educação em Computação, p. 1-10.

Wohlin, C., Runeson, P., Höst, M., Ohlsson, M. C., Regnell, B., \& Wesslén, A. (2012). Experimentation in software engineering. Springer Science \& Business Media.

PNAD - INGE 2009. Disponível em: 〈https://goo.gl/QU1dAQ> Acesso em: 23 de Julho de 2017. 